\title{
Global Conflict of the Past in Contemporary Media Space: Historical Memory in a Discursive Perspective
}

\author{
Ekaterina Y. Aleshina (a), Mark Y. Blokh (b), Tatiana A. Razuvaeva (c), \\ Hedwig Wagner (d), Anton V. Kompleev (e)
}

(a) Penza State University. Penza, Russia. Email: alcatherine[at]yandex.ru

(b) Moscow Pedagogical State University. Moscow, Russia. Email: blmy2[at]mail.ru

(c) Penza State University. Penza, Russia. Email: rastan12[at]mail.ru

(d) Europa-Universität Flensburg. Flensburg, Germany. Email: hedwig.wagner[at]uni-flensburg.de

(e) Moscow State University. Moscow, Russia. Email: an_kompleev[at]mail.ru

\begin{abstract}
The article is devoted to an overview of studies on the discursive embodiment of historical memory, particularly, in the media. The research is aimed at the overview and systematization of, predominantly, international and Russian concepts of historical memory in academic literature. The scientific significance of research results is determined by the possibility of clarifying the definitions of historical memory in the process of systematizing the existing overseas and domestic studies. With that, the "starting point" of historical memory in this research are global political conflicts, particularly, World War I and World War II. The focus of research interest is the memory of the world wars which is discursively expressed in modern media space with various pragmatic tasks. Analysis of media materials allows for revealing the mechanisms of using historical memory as a tool for creating assessment and images while covering World War I and World War II. The research makes it possible to obtain a general discursive picture of the mass consciousness and, what is especially, important, to get specific data on the linguistic "content" of historical memory reflected in online media. The article is addressed to researchers in various fields of the Humanities, journalists and a wide circle of readers who are interested in the problem.
\end{abstract}

\section{Keywords}

Historical Memory; Cultural Memory; Conflict; World War I; World War II; Discourse; Historical Discourse; Discourse of Memory

\section{(c) (1)}

This work is licensed under a Creative Commons «Attribution» 4.0 International License 


\section{Глобальный конфликт прошлого в современном медиапространстве: Историческая память в дискурсивном ракурсе}

\section{Алёшина Екатерина Юрьевна (а), Блох Марк Яковлевич (b), Разуваева Татьяна Александровна (c), Вагнер Хэдвиг (d), Комплеев Антон Вячеславович (e)}

(a) Пензенский государственный университет. Пенза, Россия. Email: alcatherine[at]yandex.ru

(b) Московский педагогический государственный университет. Москва, Россия. Email: blmy2[at]mail.ru

(c) Пензенский государственный университет. Пенза, Россия. Email: rastan12[at]mail.ru

(d) Европейский университет Фленсбург. Фленсбург, Германия. Email: hedwig.wagner[at]uniflensburg.de

(e) Московский государственный университет. Москва, Россия. Email: an_kompleev[at]mail.ru

\section{Аннотация}

Статья посвящена обзору научных трудов, направленных на изучение дискурсивного воплощения исторической памяти, в том числе, в медиа. Целью исследования является обзор и систематизация, преимущественно, зарубежных и отечественных концепций выражения исторической памяти в современной научной литературе. Научная значимость результатов исследования определяется возможностью уточнения определений исторической памяти и дискурса памяти в процессе систематизации существующих зарубежных и отечественных исследований. При этом «отправной точкой» исторической памяти будем считать глобальные политические конфликты, подразумевающие, в данном исследовании, Первую мировую войну и Вторую мировую войну. В центре исследовательского интереса - память о мировых войнах, получающая дискурсивное выражение в современном медиапространстве с различными прагматическими задачами. Как показывает обзор проведённых исследований, анализ медиаматериалов позволяет выявить механизмы использования исторической памяти в качестве инструмента создания оценок и образов в контексте освещения Первой мировой войны и Второй мировой войны, создаёт общую дискурсивную картину состояния массового сознания и, что особенно важно, позволяет получить конкретные данные о языковом наполнении исторической памяти, отражённой в онлайн-медиа. Статья адресована исследователям в различных областях гуманитарного знания, журналистам, а также широкому кругу читателей, интересующихся данной проблематикой.

Ключевые

историческая память; культурная память; конфликт; Первая мировая война; Вторая мировая война; дискурс; исторический дискурс; дискурс памяти

Это произведение доступно по лицензии Creative Commons «Attribution» («Атрибуция») 4.0 Всемирная 


\section{Введение}

Конфликт в современном мире является скорее нормой, чем аномалией, что можно объяснить как имманентностью противостояния в любом социуме, так и объективной геополитической ситуацией, связанной с разделением зон влияния на мировом пространстве на протяжении всего XX века и в последние десятилетия. Л. Козер, вместе с другими западными теоретиками конфликта (например, К. Боулдингом, Р. Дарендорфом) подчёркивает, что конфликт как социальное явление присущ любому обществу, что обусловлено постоянно происходящими постоянно в обществе изменениями. Конфликт является важнейшим элементом социального взаимодействия. В подтверждение подобной точки зрения политолог А.В. Манойло отмечает, что в современных международных отношениях конфликты выступают особой формой политического взаимодействия акторов международных отношений и мировой политики, а также являются способом разрешения противоречий, механизмом, подобным клапану выпуска пара, защищающим международные отношения от перегрева (Манойло, 2013).

Актуальность исследования исторической памяти о конфликте продиктована современной геополитической ситуацией, отмеченной чередой непрекращающихся военных столкновений, затрагивающих десятки малых и больших государств и прежде всего ведущие мировые державы, которые, в свою очередь, имеют связанные с этими войнами свои жизненные интересы - политические, экономические, культурные, бытовые. Историческая память о глобальном конфликте входит составной частью в определение политического отношения к друг другу ведущих держав, вплоть до отношения как с позиции мира, так и непримиримой вражды.

В качестве глобальных конфликтов XX века в настоящем исследовании фигурируют Первая мировая война и Вторая мировая война, определившие ход мировой истории на многие десятилетия вперед. Как Первая, так и Вторая мировая война представляет собой конфликт цивилизационного масштаба, в который были вовлечены несколько государств. Видимые обобщения, охватывающие две войны в предлагаемом обзоре, подразумевают изучение отражения памяти о конфликте в медиадискурсе в целом. Дискурсивное отражение исторической памяти обусловлено её представленностью и существованием в дискурсе, предполагающем обращение к медийным текстам в ситуации медийной коммуникации. Дискурсивная историческая память связана с проявлением исторической памяти в медийной коммуникации в определенном социально-историческом контексте. Дискурсивный ракурс выражения исторической памяти представляет особый исследовательский интерес на фоне обзора зарубежных и отечественных концепций, а также в понятийном смысле, подразумевающем трактовку данного явления. 
В статье предлагается обзор исследований, направленных на изучение исторической памяти в целом, и исторической памяти в медиа в частности. В исследовательском фокусе также обзор некоторых эмпирических исследований, направленных на изучение дискурсивного выражения исторической памяти о Первой и Второй мировых войнах в современных медиа. Эмпирические исследования различаются по критериям, положенным в основу методологии исследования. В то же время, обобщающим фактором является медиа материал и объект изучения - дискурсивное выражение исторической памяти о глобальном конфликте. Обзор теоретических работ построен по хронологии, обзор эмпирических исследований сосредоточен на современных разработках зарубежных и российских учёных.

\section{Историческая память в исследовательских концепциях}

Обратимся к истокам исследований исторической памяти. К. Яке и М. Зиролд отмечают, что несмотря на активное становление исследовательского интереса к феномену исторической памяти с конца 1980-х годов, основоположниками традиции исследования памяти следует считать М. Хальбвакса и Э. Варбурга, основные работы которых относятся к началу XX века (Jacke \& Zierold, 2015). Подобной точки зрения придерживается и А. Васильев, подчеркивающий приоритетную роль М. Хальбвакса и Э. Варбурга в исследовании феномена исторической памяти (Васильев, 2009; 2014).

Историк-искусствовед Э. Варбург занимался исследованиями памяти в практическом ракурсе: в своих исследованиях произведений искусства различных эпох и культур Э. Варбург пытался выявить «формулу пафоса» и задокументировать в своём последнем выставочном проекте «Мнемозина» своего рода память в картинах, отражающих различные исторические эпохи и культуры. Э. Варбург со своим междисциплинарным подходом может быть отнесён к создателям культурологического исследования памяти и междисциплинарного культурологического анализа. Э. Варбург ввёл в научный обиход понятие социальной памяти. Благодаря концентрации своих исследований на материалах визуальной культуры он также дал импульс развития медиалогии и культурологии.

В отличие от материально-ориентированного, дедуктивного подхода Э. Варбурга, концепция памяти французского социолога М. Хальбвакса носит теоретический характер. В то время как современники М. Хальбвакса занимались исследованием индивидуальной памяти и трактовали память исключительно как психологический феномен отдельного индивида, сам М. Хальбвакс считал, что необходимо учитывать обязательную взаимосвязь индивидуальных воспоминаний и социальных условий общества: «Не существует памяти кроме тех рамок, которые ей создают живущие в обществе люди» (Halbwachs, 1966, p. 121). В своих более поздних работах он развивает концепцию памяти поколений, вводит понятие «коллективная память» («mémoire collective») и создаёт 
основу для концепции коллективной памяти: именно на эту концепцию опирались в 1980-х годах многие ученые, исследовавшие различные формы памяти и воспоминаний общества и использовавшие понятия «коллективная память», «культурная память», «социальная память», «памятные места» и др.

Р.А. Исслер подробно рассматривает истоки возникновения понятия «культурная память», отмечая приоритет М. Хальбвакса в становлении этого понятия:

\begin{abstract}
«Тому, что память уже не рассматривается культурологией исключительно как индивидуальное и индивидуально-психологическое явление, в отличие от Зигмунда Фрейда (1856 - 1939), а как социальный феномен, мы обязаны исследованиям французского социолога Мориса Хальбвакса (1877 - 1945), который благодаря своей концепции «коллективной памяти» (la mémoire collective) учитывает социальный аспект воспоминаний и влияние общества на конструирование идентичности задолго до того, как была доказана социальная обусловленность субъективной человеческой памяти на нейрофизиологическом уровне» (Ißler, 2017, pp. 909-922).
\end{abstract}

Б. Сондергельд называет М. Хальбвакса «пионером социального исследования памяти», отмечая, что он противопоставил себя общей в то время тенденции трактовки памяти как биологически зависимого процесса и воспоминаний как исключительно индивидуального процесса, которой придерживались, например, М. Пруст со своей концепцией непроизвольной памяти («mémoire involontaire»), 3. Фрейд со своей концепцией коллективного бессознательного, К. Юнг со своей теорией биологической передачи содержимого памяти, Э. Херинг и Р. Семон со своими представлениями о биологической наследственности памяти (Sondergeld, 2010).

Как социальный психолог M. Хальбвакс полностью отказывается от физиологической, то есть нейронной, основы памяти и проецирует понятие памяти, которое прежде рассматривалось на уровне индивидуума, на уровень социальных групп. При этом в качестве центрального тезиса выступает его идея о том, что каждое индивидуальное воспоминание является коллективным феноменом. Воспоминания возникают в процессе коммуникации и взаимодействия в рамках социальных групп, в которых каждый человек принадлежит общности людей. Процесс забывания при этом рассматривается как явление, которое возникает вследствие потери социальных рамок. При этом индивидуум и группа находятся в постоянном взаимодействии: носителем памяти всегда является отдельный человек, но процессы его памяти находятся в зависимости от социальных условий коммуникации (Halbwachs, 1950; 1966).

В статье «История и память: трудная дилемма» М.М. Федорова подчеркивает, что М. Хальбвакс разрабатывал свою концепцию в противовес теории А. Бергсона, который считал, что прошлое отражается в двух формах: образах-воспоминаниях («ретроспективная память») и психологических механизмах («повторяющаяся память»). М. Хальбвакс был категорически не согласен с такой трактовкой памяти и считал, что память может быть только 
социальной. В ранних трудах М. Хальбвакс утверждал, что индивидуальная и коллективная память находятся в единых социальных рамках, а также что память является реконструкцией прошлого, которая зависит от актуального видения прошлых событий в конкретном обществе. В последующих работах, как отмечает М.М. Федорова, М. Хальбвакс проводит анализ соотношения между индивидуальной и коллективной памятью и приходит к выводу, что «индивидуальная память оказывается пересечением нескольких видов коллективной памяти» (Федорова, 2018, с. 110), следовательно, воспоминание является для конкретного индивида не реконструкцией прошлого, а реконструкцией настоящего под воздействием прошлого. В своей концепции М. Хальбвакс разделяет два мира - мир памяти и мир истории. При этом мир памяти определяется им как сфера пережитого, а мир истории - как мир концептуализации, проблематизации. «Мир истории начинается там, где кончается мир памяти» (Федорова, 2018, с. 110). Анализ соотношения этих двух понятий, осуществленный в рамках научных исследований М. Хальбвакса имел большое значение, так как позволил перевести проблематику соотношения памяти и истории в новую плоскость изучения. Теория М. Хальбвакса, на которой основываются многие научные подходы и теории, разработанные позднее, стала поворотным пунктом в понимании культуры и памяти и ознаменовала переход от восприятия культуры как феномена памяти к восприятию памяти как культурного феномена (Assman, 2002, pp. 247-249). На соотношение индивидуальной и коллективной памяти обращают особое внимание Дж. Фентресс и К. Уикхем, подчеркивающие взаимосвязь индивидуального и коллективного (Fentress \& Wickham, 1992).

В 1970-е годы интерес к проблемам памяти, анализу соотношения истории и памяти значительно возрос, что связано, в первую очередь, с появлением феномена «исторической политики». Именно в этот период П. Нора разработал концепцию «мест памяти», оказавшую значительное влияние на дальнейшее развитие теории памяти не только в зарубежной, но и в российской науке. М.М. Федорова подчеркивает, что особо значимый вывод, к которому П. Нора приходит в своих исследованиях, следующий: «Память не является чем-то фиксированным, она развивается в зависимости от устанавливаемого сообществом, вдохновляемым в этом властями, отношения к прошлому в перспективе конструируемого горизонта ожидания» (Федорова, 2018, с. 113). П. Нора также разделяет память и историю: «История это всегда проблематичная и неполная реконструкция того, чего больше нет. Память - это всегда актуальный феномен, переживаемая связь с вечным настоящим. История же - это репрезентация прошлого» (Нора, 1999, с. 19). В своей концепции П. Нора попытался описать, как происходит формирование национальной идентичности, которая кристаллизируется вокруг «мест памяти», каким образом память формируется в зависимости от отношений людей к тем или иным историческим событиям. При этом «места памяти это крайняя форма, в которой существует коммеративное сознание в истории, 
игнорирующий его, но нуждающейся в нем» (Нора, 1999, с. 26). К «местам памяти» можно отнести памятники, коммеморации, территории, слова и др.

Р.Ю. Сабанчеев проводит подробный анализ теории П. Нора в своей статье «Концепция «мест памяти» Пьера Нора как способ исторической реконструкции». Р.Ю. Сабанчеев приходит к выводу, что в исследованиях П. Нора «четко прослеживается синкретизм концепций, предложенных М. Хальбваксом, историками «Школы Анналов» и Мишелем Фуко». В то же время «изучение «места памяти» позволяет глубже понять природу коллективной памяти, роль личности и события в ней, и ее демаркацию с природой» (Сабанчеев, 2018, с. 37).

А. Эрль отмечает, что с конца 1980-х можно наблюдать возросший интерес к исследованиям концепций коллективной памяти, культуры памяти и дискурсов памяти (Erll, 2008). А. Эрль проводит анализ причин возросшего интереса ученых к данной проблематике и отмечает, что это связано, в первую очередь, с процессами исторических, политических, общественных и научных изменений, которые вызывают вопросы о необходимости коллективного измерения памяти и изучении связей между культурой и памятью. Со сменой поколений обрывается устная передача пережитых воспоминаний. Без очевидцев исторических событий общество вынуждено ограничиваться получением информации из проводимых научных исследований исторических событий. Другим важным источником знаний о прошлом служит культурная память, формирующаяся посредством медиа.

Согласимся с А. Эрль, назвавшей основным фактором изменения конъюнктуры парадигмы памяти и воспоминаний значительные изменения в области медиа коллективной памяти (Erll, 2008). Стремительное развитие компьютерной техники дало новые возможности хранения информации и спровоцировало многочисленные исследования человеческой памяти и памяти искусственного интеллекта. Новые технологии позволяют хранить большие объёмы информации. При этом закономерным образом возникает вопрос о том, кто и как должен её систематизировать, отбирать определённые факты, которые должны знать последующие поколения.

А. Эрль также считает, что возросший интерес к изучению памяти связан с многочисленными памятными событиями, которые отмечаются во многих странах (Erll, 2017). М. Каммен ещё в середине 1990-х годов назвал девять причин актуализации дискурса памяти в США, среди которых - множество исторических юбилеев в США, которые праздновались с 1980-х годов, мультикультурализм, отрицание Холокоста, воспоминания о вьетнамской войне, развитие культурных объектов (memory industry) и завершение Холодной войны (Kammen, 1995). Приведённые причины свидетельствуют о том, что память является общекультурным, междисциплинарным и интернациональным феноменом, который не может рассматриваться в контексте одной дисциплины и одного объяснения (explanatory pluralism). Половина из выделенных М. Камменом причин возросшего интереса к проблематике памяти 
подходит также и для других стран. Как отмечают Л. Радонич и Х. Уль, каждая страна может назвать национально-специфические причины возрастания интереса к памяти как к «формуле пафоса» (pathos formula) нашего времени (Radonić \& Uhl, 2016).

На рубеже веков вопросы памяти и её рефлексии стали рассматриваться в культурологическом, междисциплинарном и интернациональном контексте (Erll, 2017). В качестве культурологического феномена память играет важную роль в различных сферах культурологической практики: воспоминания и забывание инсценируются в современной литературе и искусстве. Память является главной темой в ежедневных и еженедельных газетах. Память стала предметом политических и общественных дебатов. Кроме того, посещение объектов памяти - объектов культурного наследия - стало одним из популярных форм проведения свободного времени в выходные дни. В качестве междисциплинарного феномена память стала на протяжении последних двух десятилетий ключевым понятием культурологии (Assmann, 2002).

Р.А. Исслер отмечает ключевую роль немецкого египтолога Я. Ассмана в развитии концепции культурной памяти («kulturelles Gedächtnis»). Я. Ассман первым предложил фундаментальное обоснование концепции культурной памяти. При этом следует отметить, что само понятие культурной памяти было введено ещё раньше (Assman \& Assman, 1988).

Большую известность приобрела более поздняя работа Я. Ассмана «Das kulturelle Gedächtnis. Schrift, Erinnerung und politische Identität in frühen Hochkulturen» (Assman, 1992), которая была переиздана много раз и переведена на разные языки. Данная работа является лучшим примером того, как редкая научная дисциплина (египтология) может стать толчком к изменению культурологической парадигмы. Я. Ассман стал первым учёным, который переосмыслил размышления М. Хальбвакса и 3. Фрейда в научном и общественном контекстах и с учётом новых тенденций в понимании форм воспоминаний, ввёл новое понятие культурной памяти и создал систематизированную теорию культурной идентичности. Согласно этой теории, именно культурная память играет центральную роль в культурной эволюции человечества, формирует идентичность родовой группы, государства, нации. Этот процесс осуществляется посредством постоянной циркуляции культурных смыслов, то есть посредством коммуникации. Причём средства коммуникации могут быть как речевыми, так и неречевыми (например, архитектурные здания, письменность, ритуалы, обычаи и т.д.), благодаря которым вырабатываются групповая солидарность, коллективная идентичность. На конкретных примерах Египта, Древнего Израиля, Греции, Месопотамии Я. Ассман исследует причины зарождения общества, религиозных общин, интереса к истории, а также этапы формирования национального самосознания. Для Я. Ассмана культурная память - непрерывный процесс, в котором каждый социальный слой аккумулирует и реконструирует знание о себе и своей идентичности в форме 
культурной памяти. Культурную память следует понимать как форму трансляции и актуализации культурных смыслов.

Поскольку воспоминания не передаются по наследству, а так же, как непосредственная устная коммуникация («коммуникативная память») по биологическим причинам являются стабильными от шести до восьми десятилетий, принадлежность индивида к культурному, политическому или этническому коллективу требует постоянного обновления, подтверждения, с целью преодоления разрыва между информацией о прошедших событиях, получаемой из первых рук, и актуальной действительностью. Эти функции установления «мостов» между прошлым и настоящим и берет на себя культурная память. Будучи вневременным и внеиндивидуальным, не связанным непосредственно с конкретной личностью, феноменом, культурная память одновременно выполняет общественные обязательства и сохраняет для коллектива символические знания и ценные данные, информацию и практики от забвения. Кроме того, она отвечает на вопрос: «Что нам нельзя забывать?» (Assman, 1992, p. 30).

Исследования своего супруга продолжает А. Ассман. В своей рецензии на книгу А. Ассман «Der lange Schatten der Vergangenheit. Erinnerungskultur und Geschichtspolitik» (Assman, 2006) И.П. Давыдов отмечает, что в данной работе А. Ассман продолжает систематизацию и уточнение понятий, которые уже были введены в научный оборот Я. Ассманом, в частности, «миметическая память», «предметная память», «коммуникативная память», «культурная память», «мнемотоп», «миф», «мифомоторика» (Ассман, 2004). Она систематизирует эти понятия и представляет материал в виде информативных таблиц, демонстрирующих сходства и различия в трактовке этих понятий. К примеру, если индивидуальная и социальная память имеют биологическую / церебральную основу, то коллективная политическая память и индивидуальная культурная память - символическую. Социальная память «контагиозна», носит «межпоколенческий» характер, так как транслируется непосредственно через воспоминания старших, а культурная память «инициационна», носит «транспоколенческий» характер, так как коммуникация осуществляется с использованием символов, знаков, ритуалов, монументов, памятных дат и прочих «крупных нарративов», отмеченных «реперными точками» в пространстве и календарными «вехами» во времени. Как отмечает И.П. Давыдов, история и память, согласно концепции А. Ассман, являются не взаимоисключающими (как считали М. Хальбвакс и П. Нора), а взаимодополняющими феноменами, которые способны переходить друг в друга: историческая констатация факта приобретает черты мемориализации, если основана на субъективном переживании события и его этической квалификации (Давыдов, 2015).

Понятие политической памяти используют Ф. Форет и О. Каллигаро (Foret \& Calligaro, 2012) в процессе исследования европеизации исторической памяти. Исследователи определяют политическую память как перспективу в прошлое, которая постоянно пересматривается в процессе борьбы за политическую 
власть. Понятие политической памяти, которое стало активно использоваться с 1990-х годов, может быть использовано относительно европеизации национальной памяти «изнутри», относительно нарратива конструирования европейских институтов, а также выработки нарратива о происхождении европейской национальной истории, которая предполагает рассмотрение Европы как континента.

А. Ассман анализирует будущее памяти о Холокосте и приходит к выводу, что точкой отсчета новой эпохи для всех стран Евросоюза является именно 1945 год - победа союзников над фашистской Германией. В этом смысле Европа является мемориальным сообществом, которое призвано хранить память о величайшей трагедии XX века и не допускать её повторения. А. Ассман предлагает ряд «правил толерантного обращения с коллективной памятью» (Ассман, 2014, сс. 290-296): различение субъективных воспоминаний и объективных аргументов; запрет на оправдание одной вины за счёт другой (запрет на двустороннюю реституцию или взаимозачет потерь); запрет на конкуренцию между жертвами (худшее не отменяет плохого); приоритет инклюзивности воспоминаний; преодоление разделяющих воспоминаний и обид; контекстуализация; выработка идентификационных и ценностных рамок национальной, религиозной и любой другой идентичности.

Резонансной стала работа П. Рикёра «Память, история, забвение». В своей книге учёный пытается дать ответ на вопрос: что такое «справедливая память». Он считает, что к памяти необходимо относиться критически - необходимо осуществлять тщательный анализ исторических событий с целью предотвращения злоупотребления памятью (Рикёр, 2004, с. 331). Как подчёркивает М.М. Федорова, П. Рикёр отмечает большую значимость мемориальных требований для общества в целом, но в то же время утверждает «необходимость воли для регулирования отношений к прошлому» (Федорова, 2018, с. 118).

Проведя анализ основных концепций теорий соотношений истории и памяти, М.М. Федорова приходит к выводу, что история и память неразрывно связаны друг с другом, и что «для нормально функционирующего общества проблема состоит не в том, чтобы развести историю и память, ...а в том, чтобы разрешить вопрос, каким образом можно связать историю, память и забвение» (Федорова, 2018, с. 119).

Определяющее влияние на формирование концепций культурной памяти оказали труды Ю.М. Лотмана - известного отечественного литературоведа и культуролога. В своей работе «Память в культурологическом освещении» Ю.М. Лотман анализирует соотношение понятий «культура» и «память» с точки зрения семиотики (Лотман, 1992), предлагая рассматривать пространство культуры как «пространство некоторой общей памяти». При этом память культуры «не только едина, но и внутренне разнообразна». Учёный выделяет «память информативную» и «память креативную (творческую)» и предлагает рассматривать в качестве примера творческой памяти память искусства. Особую роль для памяти при этом играют тексты, которые 
могут актуализироваться либо деактуализироваться: неактуальные тексты «не исчезают, а как бы погасают, переходя в потенцию» (Лотман, 1992, сс. 200-202). Ю.М. Лотман пишет, что «каждая культура определяет свою парадигму того, что следует помнить (т.е. хранить), а что подлежит забвению». Однако со временем система культурных кодов изменяется, и, следовательно, меняется «парадигма памяти-забвения». Появляются новые коды, меняются тексты, развивается культура, причем траектория развития культуры может быть различной. Анализируя соотношение культуры и памяти, Ю.М. Лотман приходит к выводу, что «память не является для культуры пассивным хранилищем, а составляет часть её текстообразующего механизма» (Лотман, 1992, сс. 200-202).

Науки о древности, религиоведение, социология, политология, история, литературоведение и искусствоведение, медиалогия, педагогика, философия, психология и нейрология также занимаются исследованиями взаимодействия культуры и памяти. Память стала и интернациональным феноменом. «Memory-boom» в обществе и в науке, как отмечает А. Хюссен, произошёл в конце XX века в Германии, США, Израиле, Великобритании, Нидерландах, Южной Африке, Австралии, Канаде и в Аргентине (Huyssen, 1995). Религия, идеология, этнос, поколение и род относятся к центральным характеристикам коллективной памяти в условиях транскультурных и транснациональных обществ. «Память» и «воспоминания» как концепт и практика выходят за границы отдельных культурных областей, дисциплин и наций. Взаимодействие культуры и памяти не может быть изучено в рамках отдельной дисциплины. В связи с вышесказанным, представляется справедливым мысль о том, что «память и воспоминание не только относятся к трансдисциплинарной области научных исследований, которые не могут проводиться в рамках какойто одной конкретной дисциплины, но и требуют постоянного взаимодействия между различными областями научных исследований» (Pethes \& Ruchatz, 2001). Интеграция психологических, когнитивных, социологических, исторических, теологических, философских исследовательских подходов выступает ключевой характеристикой современных исследований исторической памяти.

Й. Рюсен и Ф. Йегер считают, что современные дебаты о культуре воспоминаний и культурной памяти следует рассматривать в контексте изменившейся культурно-исторической парадигмы, которая появилась в европейской исторической науке несколько лет назад (Rüsen \& Jaeger, 2001). В рамках этой новой парадигмы культурные восприятия, познания, нормы поведения и воспоминания, не являющиеся предметом исследований в социологических и общественных науках прежде, стали рассматриваться в новых контекстах. Общественная и социальная история получила новый импульс научных исследований к познанию и воспоминаниям индивидуальных субъектов и утверждала, что специфическая задача науки заключается, прежде всего, в том, чтобы перешагнуть за горизонт опыта и воспоминаний действующих героев исторического события. 
Новые тенденции в науке, связанные с возросшим исследовательским интересом к феномену исторической памяти, названные Я. Ассманом «новой парадигмой» (Assmann, 1988), можно проследить и в современных отечественных публикациях. Как отмечают Д.А. Аникин, А.Ю. Бубнов, А.В. Комплеев, последние двадцать лет стали временем активизации символической политики в России (Аникин, Бубнов, \& Комплеев, 2020). К примеру, анализ мемориальных проектов, осуществлённых по инициативе или при участии Российского исторического общества, показывает существенное преобладание проблематики, посвящённой масштабным историческим юбилеям. Из более чем двадцати проектов, осуществлённых Российским историческим обществом в 2012-2019 гг., одиннадцать посвящены коммеморации юбилейных дат российской истории.

В связи с пересмотром научного и общественного понимания социальной истории в последние десятилетия, дискурс воспоминаний и памяти приобрёл более четкие контуры. Дискуссии об исторической антропологии и истории культуры 1980-х годов стали импульсом для современных дебатов о воспоминании и памяти, в рамках которых было переосмыслено и по-новому представлено значение субъективных воспоминаний, форм восприятия и интерпретации действительности отдельными субъектами и социальными группами.

С обращением к культуре воспоминаний историческая наука теряет привилегии исключительно культурного воспоминания: историческое мышление трансформируется от институализированных научных мероприятий экспертов в сеть социальной коммуникации между конкретными индивидуумами и группами, которые конкурируют друг с другом в получении интерпретаций, значений и символов. Ю. Кока в своих ранних научных работах по исторической социологии сформулировал историческую научную концепцию в виде фразы «переход к аналитической парадигме», которая стала господствовать в исторической социологии в 1970-х годах:
«Историки отказались от традиционных форм изложения событий. Их форма коммуникации, в том числе и с публикой, стала аргументированнее, концеп- туальнее, взвешеннее и саморефлексивнее. Собственно наука стала рассматри- ваться как часть общественного просвещения. Историей стали заниматься, чтобы извлекать из неё уроки, а также для того, чтобы освободиться от неё» (Kocka, 2000, p. 10).

В контексте новой парадигмы исторической социологии историческое знание дало возможность по-новому рассмотреть факторы и причины исторических изменений в прошлом, которые возникают из обычных воспоминаний и рассказов субъектов и опираются на действительность с повседневными познаниями, ориентациями и трактовками.

«Концепция общества скорее задаёт вопрос о таких ресурсах, неравенствах и отношениях власти, которые в своё время не были закреплены коммуникативно, не были выражены в виде символов и возможно остались незамеченными 
современными действующими лицами, в то время как концепция культуры обращает внимание на те сферы действительности, которые были доступны действующим лицам в виде объекта коммуникации и символа» (Kocka, 2000, p. 19).

По этой причине историческая наука стала институтом, который перерабатывает информацию из воспоминаний людей о тех или иных исторических событиях, при этом выходя за рамки этой полученной информации. Историческая наука стремится получить более достоверную информацию и интерпретацию событий, не ограничиваясь субъективными и зачастую односторонними воспоминаниями очевидцев.

В российской исторической науке появились различные варианты социального и культурно-исторического подходов, появился интерес и к проблематике культурной памяти. Это свидетельствует о признаках интеграции российских исследований в мировую историческую науку (Глебова, Большакова, \& Минц, 2013).

В статье «Media memory in the digital world» Д.С. Артамонов, М.Л. Воловикова, С.В. Тихонова проводят анализ формирования исторической памяти в современном цифровом мире (Artamonov, Volovikova, \& Tikhonova, 2019). Авторы описывают процесс появления новой формы исторической памяти в условиях цифровой эпохи и предлагают определить её как «медийную память». Библиотеки, исторические архивы, музеи больше не являются единственными источниками хранения исторической памяти, появляются электронные базы данных, которые доступны большому кругу пользователей Интернет-пространства. Под медийной памятью Д.С. Артамонов, М.Л. Воловикова, С.В. Тихонова предлагают понимать «цифровую систему хранения, преобразования, производства и распространения информации о прошлом, на основе которой формируется историческая память людей и сообществ» (р. 3). Авторы считают, что медийную память можно рассматривать как виртуальный социальный механизм запоминания и забвения. Этот механизм обладает способностью обеспечивать различные формы представления истории в пространстве повседневной жизни, расширять представление и воспоминания о прошлом, а также увеличивать количество людей, создающих и потребляющих содержимое памяти.

Современное общество переживает бум памяти, связанный со способностью пользователей создавать знания о прошлом и делиться ими с помощью новых медиа. Таким образом, память переносится из личного и культурного пространства в средства массовой информации. Развитие медийной памяти становится проблемой для исторической эпистемологии, так как требует разработки совершенно новых подходов, которые могут описывать цифровые методы познания прошлого группами индивидов и оценивать их. 


\section{Историческая память и современные медиа. Дискурсивная историческая память}

В условиях цифровизации медиа вопрос о соотношении исторической памяти и СМИ стал еще более актуальным, поскольку так называемые «базовые технологии» проникли во все сферы человеческой жизни (Zierold, 2006; van Dijck, 2007; Mayer-Schönberger, 2010; Garde-Hansen, 2011). Расширение медийных онлайн-сетей приводит к изменению возможностей хранения и архивации информации, к изменению связей между частными и общественными воспоминаниями и новыми формами воспоминаний и памяти во всемирной паутине. Д. Хайн, Г. Зебальд, В. Зоммер (Hein, 2009; Sebald, 2018; Sommer, 2018) анализируют концепции, рассматривающие взаимосвязь медиа, в том числе, цифровых медиа, и памяти, обращаясь к ключевым концепциям, разработанным М. Хальбваксом, Я. Ассманом, А. Ассман, А. Эрль.

М. Хальбвакс не рассматривал медиа в качестве составляющей теоретической концепции коллективных процессов памяти. Однако в своем труде «Das Gedächtnis und seine sozialen Bedingungen» (Halbwachs, 1966) он впервые пишет о медиатизации воспоминаний, описывая случай девушки-инуитки, проявляющей эмоции и вспоминающей прошлое своей родины при виде фотографий других представителей народа инуитов. Тем не менее, как подчеркивает В. Зоммер, в научном труде М. Хальбвакса размышления о медиа представлены достаточно слабо, что, связано с тем, что медиалогия еще не была сформирована как отдельная научная дисциплина (Sommer, 2018).

Начиная с 1980-х годов Я. Ассман и А. Ассман стали активно изучать аспект отражения памяти в медиа. При этом они подчеркивали «освобождение ситуации» посредством письменности (Assmann, Assmann, \& Hartmeier, 1983). Их понятие культурной памяти по сравнению с теорией М. Хальбвакса развивается как «объективированная культура», которая имеет «совокупность текстов, картин и обычаев, характерных для каждого общества и каждой эпохи» (Assmann, 1988), со своей структурой знания и своей формой памяти. При этом медиа выполняют функцию хранилища и обеспечивают «переход из коммуникативной в культурную память» (Assmann \& Assmann, 1994). Однако, как справедливо отмечает В. Зоммер (Sommer, 2018), если исходить из того, что в современном обществе почти каждая форма коммуникации опосредована медиа, тогда в особенности для онлайн-коммуникации уровни коммуникативной и культурной памяти едва ли могут быть отделены друг от друга.

Концепция А. Эрль является более близкой к актуальным теориям медиа, чем подход Я. Ассмана и А. Ассман. Согласно А. Эрль, содержательные элементы медиа передают знания о прошлой действительности, при этом они не являются «нейтральными носителями», так как оставляют свои отпечатки на содержании. При этом медиальные аппараты создают «миры коллективной памяти в соответствии со своими характеристиками и возможно- 
стями». При этом индивидуумы остаются носителями коллективной памяти (Erll, 2004).

Вышеупомянутые концепции концентрируются, прежде всего, на общепринятых медиа, рассматривают только эксплицитные события прошлого как объекты памяти, определяют социальные формы памяти преимущественно из индивидуальной перспективы или перспективы интеракции, так что при этом другие уровни социальных процессов и в особенности логика в культурных, социальных и технических процессах не входят во внимание. С одной стороны, это приводит к тому, что только одна часть из событий прошлого изучается в рамках этих концепций, а с другой стороны, не учитывается специфика цифровых медиа. Х. ван Дейк разработала концепцию медиатизированной памяти (mediated memories) (Dijck van, 2007), проведя исследование изменений индивидуальной и коллективной памяти под воздействием процессов цифровизации, в рамках которого были рассмотрены взаимосвязи между сознанием, технологией и культурой. Проанализированную «индивидуальную культурную память» Х. ван Дейк рассматривает как акты и продукты воспоминаний, которые производят индивидуумы, чтобы придать своей жизни определённый смысл по отношению к другим жизням, а также чтобы определить своё место во времени и в пространстве. Память в этом смысле имеет динамичную форму, которая передаётся и реализуется между собой и иным, между частным и общественным, между индивидуальным и коллективным. Соответственно, новое цифровое пространство открывает новые формы связей памяти, новые формы индивидуального определения своего места во времени и пространстве. Они изменяют природу воспоминания, так как интегрируются в повседневную рутину развития индивидуума. Таким образом, $\mathrm{X}$. ван Дейк исходит из того, что медиа и воспоминания настолько взаимосвязаны друг с другом, что их нельзя рассматривать как отдельные явления. При этом X. ван Дейк придерживается концепции медиатизации, в рамках которой процессы коммуникации понимаются как «слияние» поведения, обусловленного медиа, и поведения, не обусловленного медиа (Неpp, 2011).

Дж. Гард-Хансен, Э. Хоскинс, А. Рединг в своем совместном труде (GardeHansen, Hoskins, \& Reading, 2009) констатируют пронизанность повседневной жизни непрерывным документированием с помощью цифровых медиа. Опираясь на концепцию Э. Гросц (Grosz, 1999), авторы определяют цифровую память (digital memory) как активное, субъективное, органичное, эмоциональное, виртуальное и неопределенное производство прошлого и настоящего в одно и то же время. При этом цифровая память находится в пространстве между историей и памятью, между органическим и неорганическим, между старыми и новыми технологиями. При этом авторы концепции отмечают степень персонализации событий, нарративов и свидетельств (Garde-Hansen, Hoskins, \& Reading, 2009).

Исследуя политико-экономический контекст глобальных сетевых цифровых технологий, А. Рединг отмечает существование глобальной 
цифровой памяти (globital memory) (Reading, 2014). В своей взаимосвязи мобильность, глобализация и медиатизация оказывают воздействие на конструирование пространства и времени, на концентрацию и потоки капитала и трудовых ресурсов (Keightley \& Reading, 2014). В этих работах и в более поздней монографии (Reading, 2016) А. Рединг устанавливает взаимосвязи между практикой и политико-экономическими структурированиями, между материальным и медиативным с одной стороны, между мобильностью и глобализацией с другой стороны, переводя фокус на индивидуальные достижения памяти.

Е. Эспозито рассматривает вопросы взаимосвязи памяти и цифровых медиа исходя из концепции социальной памяти. Она фокусирует внимание не на понятии групповой коллективной памяти, а на понятии социальной памяти, подразумевая под ней «вид и способ обращения общества с прошлым и будущим, способ использования опыта для ориентирования в способах поведения и коммуникации (исходя из того, что думает один или несколько индивидуумов по отдельности) (Esposito, 2013). Опираясь на медиальные изменения, Е. Эспозито исследует социальную память современного общества. Кажется, что цифровые технологии позволяют помнить все и также продуцируют информацию, которая «доступна, хотя о ней не размышляли ранее и не обсуждали её» (Esposito, 2013, p. 96).

По утверждению В. Зоммер (Sommer, 2018), проблематичным в концепции Е. Эспозито является отождествление интернета как информационно-коммуникационной технологии с возможностями воспоминания о социальных системах. Если следовать этому утверждению, получается, что все, что сохранено с помощью информационно-коммуникационных технологий и может быть найдено в сети, потенциально пробуждает воспоминания о социальных системах.

Анализируя классические концепции исторической и культурной памяти, В. Зоммер заключает, что использование концепции медиатизации является продуктивным для изучения воздействия процесса цифровизации и изменений медиа на социальные процессы воспоминаний (Sommer, 2018, p. 76). B. Зоммер отмечает, что дальнейшего развития теории медиатизации можно принять положение о том, что процессы медиатизации рассматриваются как процессы изменения медийного пространства, которые определяются не медийными технологиями, а пользователями этих технологий, которые применяют и адаптируют медиа. Благодаря этому удастся избежать технико-ориентированной перспективы, в рамках которой технологии определяют конструирование прошлого. Воспоминания следует рассматривать как активный процесс, который встраивается в медийную повседневность индивидуумов. В этом случае в фокусе теоретического рассмотрения медиальных воспоминаний находятся не цифровые медиа, а скорее действия индивидуумов. Подобная перспектива позволяет описывать взаимосвязи между медиа и воспоминаниями не как одностороннее воздействие, а учитывать людей как 
активных «вспоминателей», и описывать это взаимодействие как взаимные и взаимосвязанные процессы, поскольку медийные технологии отражают и модусы воспоминаний.

Продолжая свои рассуждения, В. Зоммер отмечает, что медиа и воспоминания можно рассматривать как элементы одного процесса. При этом если исходить из «слияния» поведения, обусловленного медиа, и поведения, не обусловленного медиа, невозможно будет разграничить два соответствующих типа воспоминаний. Смена перспективы на вспоминающих индивидуумов и слияние медиа и воспоминаний в медиатизированные воспоминания могут привести к разрешению часто обсуждаемой дихотомии индивидуальных и общественных процессов воспоминаний. Вместо дихотомии связь между индивидуальным и общественным воспоминанием может быть представлена в виде оси, на которой могут располагаться не только исключительно индивидуальные и исключительно общественные ссылки на прошлое, но и смешанные формы, в которых с позиции вспоминающих индивидуумов индивидуальные воспоминания трансформируются в общественные процессы воспоминания и памяти, и наоборот. В. Зоммер также считает, что для дальнейшего развития концепций взаимодействия медиа и памяти (Sommer, 2018) необходимо учитывать концепцию трансмедиальности: при таком подходе анализируются не отдельные медиа или коммуникационные технологии, а конвергентные медиальные сети - это позволит в теоретических исследованиях приблизиться к реальному повседневному использованию медиа, в рамках которого порой невозможно разделить различные медиа. Это позволит рассматривать медиатизированные воспоминания как трансмедиальные.

В монографии «Silence, Screen, and Spectacle: Rethinking Social Memory in the Age of Information and New Media» под редакцией Л. Фримана, Б. Ненаса и Р. Дэниела (Freeman, Nienass, \& Daniell, 2014) отмечено, что новые социальные сети меняют способ восприятия настоящего и прошлого, причем прошлое может быть проанализировано с помощью метафор «тишина», «экран» и «перформанс».

Д.С. Артамонов, Е.Н. Медведева, С.В. Тихонова, М.Л. Воловикова в статье «Holy Selfie as the Channel of Media Memory in the Digital World» отмечают, что медийная память субъективирует историческое знание, выделяя значимую в общественном понимании информацию. Историческое знание сегментируется в разных элементах медиасферы и демонстрируется в разных Интернетисточниках разной целевой аудитории. Медийная память характеризуется преобладанием личной и семейной памяти, в которой представления о прошлом основаны на личных эмоциональных переживаниях. Медийная память демократична, поскольку создается на основе свободного выражения мыслей людей посредством языка. Историческая информация, производимая и распространяемая индивидом служит личным и идеологическим целям, на основе которых человек формирует свою идентичность и 
взгляд на мир. Медийная память становится историческим измерением постправды, в котором личная история и личный опыт заменяют объективные факты. При этом holy selfie являются инструментом, подтверждающим историческую объективность религиозного опыта, в котором проявляется отношение к религиозным местам памяти (Artamonov, Medvedeva, Tikhonova, Volovikova, 2021, p. 20).

Более того, медиа не только распространяют, но и конструируют представления о прошлом при помощи «мемуарных и коммеморативных практик, массовых и локальных цифровых краудсорсинговых проектов, в историческом сегменте сетературы ${ }^{1}$ и видеоблогинга, что наглядно демонстрирует специфический вид пользовательской активности, который можно обозначить как хисторихакинг» (Артамонов \& Тихонова, 2020).

«Понятие «хисторихакинг» было обнаружено нами в западном сегменте индустрии научно-популярных развлечений, этим словом обозначают интерактивные исторические квесты с элементами дополненной реальности. Также оно встречается в жанровой историческо-фантастической литературе, объединяя тематику прогрессорства, попаданчества и альтернативной истории. На наш взгляд, хисторихакинг можно определить как изменение исторического знания, которое способно удовлетворить запрос общества на актуальную память о прошлом, невзирая на истинность или ложность исторических фактов. Хисторихакер провозглашает истинность знания, угождая общественной потребности, а не в силу очевидности исторического факта... Этот тренд демонстрирует массовую интенцию на освоение и приватизацию макроистории, включения её в переработанном виде в пространство личности и создание собственной субъективной картины исторической реальности» (2020).

Представления о прошлом, распространяемые в медиа, могут носить мифологический характер. А.А. Линченко, С.В. Тихонова, И.П. Полякова, А.Г. Иванов комплексно исследуют основополагающие практики конструирования социальных мифов в современных медиа, вместе с особенностями их воздействия на массовое сознание, а также масштабом их влияния на коммеморативное пространство. Медианарративы исследованы на предмет наличия мифов различного смыслового наполнения. Современная мифология рассматривается параллельно с идеологией (Иванов, Тихонова, Линченко, \& Полякова, 2020).

Принимая во внимание рассмотренные концепции, подчеркнём коммуникативную составляющую как основную характеристику медиа. Все существующие в медиа индивидуальные и общественные взаимосвязи получают реализацию в коммуникации, а точнее, в дискурсе. Понятие дискурса, получившее различные трактовки в концепциях зарубежных и отечественных исследователей (Т. ван Дейк, Дж. Лемке, Д. Шиффрин, В.А. Звегинцев, В.З. Демьянков, В.И. Карасик и др.), остается в центре научных дискуссий в связи со своей многоаспектностью и неоднозначностью. Обратимся к опре-

1 Сетевая литература (прим. редактора) 
делению дискурса, данному в контексте лингвистических теорий языка, речи и текста.

Дискурс - это «тематически определенный текст, задуманный и предполагаемый как целый и завершенный, но рассмотренный в ситуации общения, в которой он разворачивается» (Блох, 2013, с. 9). Иными словами, дискурс есть текст in statu nascendi, в момент создания. При этом особую роль играет социальный контекст, включающий в себя ситуацию общения (речевую ситуацию), обусловливающий лингвосоциальную природу дискурса. Именно дискурс является частным понятием относительно текста. При этом текст возведен «в общее понятие речи, выделенное и определённое единой темой» (Блох, 2013, с. 9). Таким образом, определение текста обусловлено понятием речи. Речь представляет собой словесное выражение мыслей, которое может иметь разные характеристики связности, завершённости и тематизации.

\begin{abstract}
«Каждый текст является продуктом акта речевого общения в контексте культуры, которая представляет собой необъятную совокупность текстов либо самодостаточных и непосредственно фиксированных определенной формой записи, либо нефиксированных, но тем или иным образом связанных с необъятной совокупностью артефактов вместе с их номинациями и понятийными толкованиями, передаваемыми соответствующими экспликациями и импликациями» $(2013$, с. 5$)$.
\end{abstract}

Культура, являясь системой интеллектуальных ценностей общества, неразрывно связана с языком как системой вербальных инструментов для создания этих ценностей. Любая общественная идея или действие рождаются, готовятся, реализуются и контролируются с помощью языка. Сфера медиа составлена множеством медиатекстов различного типа, характеризующихся определенной структурой и целевыми установками - от статьи в онлайн-газете до инстаграм-поста или блога. Подчеркнём дискурсивный характер медийной коммуникации, определяемой коммуникативной ситуацией по законам медиа.

Принимая во внимание приведённую выше трактовку дискурса, определим исторический дискурс как текст, отмеченный темой, имеющей отношение к историческим событиям и рассмотренный в ситуации воспоминания об этих событиях. Таким образом, мы можем считать исторический дискурс дискурсом памяти (Алёшина, 2021). Дискурс памяти можно обнаружить в разных сферах коммуникации: от политической риторики до каждодневных разговоров. Присутствием дискурса памяти отмечена и медийная коммуникация. Как сложное социально-коммуникативное явление дискурс памяти является одновременно социальной движущей силой, а также объектом изменений, проявляющихся, в том числе, и в медиа. Эволюция дискурса памяти в меняющемся мире вызвана внешними и внутренними факторами, которые можно считать факторами регуляции коммуникации. Медийные материалы, медиатексты, имеющие отношение к событиям прошлого, представляют 
дискурс памяти, отмеченный, в свою очередь, присутствием исторической памяти.

Историческая память есть отражение в сознании людей некоторого факта истории, который, будучи зафиксированным в памяти, представляет собой устойчивый элемент массового сознания. Данный факт, как правило, привлекает по различным причинам внимание средств массовой информации, создающих условия для поддержания общественного интереса в массовом сознании путём распространения и хранения информации. Историческая память находит выражение в коммуникации, точнее в дискурсе, в медиадискурсе в частности.

Определим дискурсивную историческую память как реализуемое в дискурсе отражение в сознании человека исторических фактов. При этом речь идёт о фиксации в индивидуальном и массовом сознании событий прошлого, информация о которых выражена посредством коммуникации. Сама историческая память не может не быть комментирующей, оценивающей, морализирующей. Однако ее дискурсивное выражение может предполагать оценку событий прошлого, либо их переосмысление и комментирование.

Особый исследовательский интерес представляет дискурсивное отражение глобальных конфликтов прошлого в медиа. Исследования медийных публикаций, посвящённых Первой и Второй мировым войнам? основаны на различных методологических принципах. Обратимся к обзору некоторых российских и зарубежных эмпирических исследований последних лет, которые позволят получить представление о состоянии дискурсивной исторической памяти о Первой и Второй мировых войнах.

\section{Дискурсивное отражение истории конфликта в медиа: обзор исследований}

Изучением репрезентации дискурса исторической памяти о Первой мировой войне в современных онлайн-медиа активно занимается международный консорциум LEMEL «L'Europe dans les medias en ligne / Studying the media coverage of European issues by online media» (https://lemel.hypotheses.org/) в рамках реализации проекта DIREPA. В его состав входят медиологи, лингвисты, социологи и историки из Франции, Германии, Италии, Польши, Румынии, Канады и России. Целью консорциума является объединение исследователей, занимающихся изучением медийного дискурса, дискурса исторической памяти и его отражения в онлайн-медиа, проведение сравнительносопоставительного анализа отражения европейской тематики в онлайн-медиа различных стран. Методы сбора анализа информации, её кодирования и обработки были определены руководителями консорциума - Л. Радут-Гахи (Университет Сержи Понтуаз, Франция) и Х. Вагнер (Европейский университет Фленсбург, Германия) (Вагнер \& Алёшина, 2019). Результаты исследований, полученных в ходе реализации проекта DIREPA, отражены в коллективных 
монографиях «Отражение прошлого Европы в онлайн-медиа» (Вагнер \& Алешина, 2019) и «Media Discourse of Commemoration. The Centenary of World War One in Europe» (Le, Radut-Gaghi, Silletti \& Wagner, 2021).

$\mathrm{X}$. Вагнер проводит анализ репрезентации памяти о Первой мировой войне в онлайн-газетах пяти европейских стран (Франции, Германии, Италии, Польши и России). Было проанализировано свыше 200 статей, отобранных в период 07.11.2018 - 14.11.2018 на онлайн-порталах газет Allgemeine Zeitung (FAZ, Германия), Gazeta Wyborcza (GW, Польша), Rzeczpospolita (RZ, Польша), Rossiiskaya Gazeta (RG, Россия), Vedomosti (Россия), La Repubblica (LR, Италия), Corriere della Sera (CDS, Италия). В своем исследовании X. Вагнер опирается на теорию транснациональной культуры памяти (de Cesari/Rigney, 2014), теорию европеизации исторической памяти (Rigney, 2014), а также на концепцию нарративов об истории Первой мировой войны.

В процессе анализа медийного корпуса Х. Вагнер выделяет следующие нарративы о Первой мировой войне, характерные для немецкого, французского, итальянского и польского корпусов:

а) бессмысленность войны / гуманистско-пацифистские размышления о войне;

b) культурная память и историческая политика;

с) франко-германский проект - за будущее Европы (Вагнер, 2019).

В русском корпусе, согласно мнению Х. Вагнер, основными журналистскими нарративами являются следующие:

а) «забытая война» - культурная память как пересмотр забывания Первая мировая война и Октябрьская революция в России;

b) культурная память и воспоминания - памятники и музеи истории;

c) уроки истории (Le, Radut-Gaghi, Silletti, \& Wagner, 2021).

Анализируя корпус с точки зрения отражения тенденций европеизации исторической памяти, Х. Вагнер приходит к следующим выводам (Вагнер \& Алёшина, 2019). Согласно результатам анализа немецких, французских, итальянских и польских статей о праздновании Первой мировой войны, 2018 год знаменует начало повествования о Первой мировой войне как об основании единой Европы; целью проводимых торжественных церемоний является провозглашение европейских ценностей: против национализма, за право на свободу, отстаивание мира и борьба за демократию; национальные места памяти становятся европейскими, новое повествование о Первой мировой войне делает ее местом памяти или событием для сохранения европейского мира в Европе.

Таким образом, западноевропейские и центральноевропейские нарративы демонстрируют признаки конвергенции и обеспечивают общую основу, 
которая может служить фундаментом для построения нового нарратива. В русском же корпусе отражается стремление сохранения национальной идентичности, в то же время наблюдается тенденция к обсуждению европейской транснациональной коллективной памяти.

Э. Ле проводит анализ медийного корпуса французской онлайн-газеты Le Monde, немецкой газеты Süddeutsche Zeitung и британской газеты The Guardian, используя лексикометрический анализ с использованием компьютерной программы Iramuteq (http://www.iramuteq.org/) (Le, RadutGaghi, Silletti, \& Wagner, 2021). На основе проведенного компьютерного анализа были выявлены тематические кластеры, связанные с европейской тематикой. Анализ этих кластеров показал, что все три онлайн-газеты освещают общие вопросы, обладающие, в то же время, национальной спецификой. Например, The Guardian связывает Первую мировую войну, брексит и строительство новой Европы. Le Monde, также связывая Первую мировую войну и брексит, продвигает идею общеевропейского консенсуса. Süddeutsche Zeitung заявляет об официальных проевропейских позициях, способствует продвижению идеи строительства единой Европы.

Э. Ле приходит к выводу, что кажущееся отсутствие европейской транснационализации памяти о Первой мировой войне не помешало всем трём онлайн-газетам конструировать европейскую принадлежность вокруг воспоминаний о Первой мировой войне, т.е. воспоминания могут различаться по тому, как они выражены, но их все же можно использовать для общей цели. Таким образом, все три газеты участвовали, каждая со спецификой своего национального контекста, в построении общеевропейской «общественной памяти».

Отметим, что процесс формирования транснациональной памяти был рассмотрен в работах Э. Сангара (Sangar, 2015, p. 77). Коллективная память может приобрести транснациональный характер, когда представители разных политических сообществ «дискурсивно вовлечены» в одно и то же повествование. Транснациональная коллективная идентичность формируется, когда акторы вместе участвуют в общем нормативном проекте (в плане нормативных целей и ценностей), который берет начало в указанном повествовании.

Дискурсу прошлого посвящена работа Л.В. Коротецкой (2018). Исследование посвящено изучению поля коллективной памяти Германии: проанализированы интерпретации прошлого и коммеморативные практики, развиваемые в медийном дискурсе. Особое внимание уделено дискурсивной силе нацистского прошлого и его значению для осовремененного немецкого общества. Л.В. Коротецкая приходит к выводам о том, что в медийном немецком дискурсе установилась максима о самовосприятии немецкой идентичности как основанной на этнической парадигме, связанной с обеспечением ответственности немецкой нации за преступления прошлого. В качестве одного из условий интеграции выступает присоединение к памяти о Холокосте. Коммемора- 
тивные традиции, проявляющиеся в немецком обществе, анализируются Л.В. Коротецкой относительно современных политических проблем, например, проблемы интеграции мигрантов в Германии.

В преддверии празднования 75-летней годовщины Победы в Великой Отечественной войне в 2019 году возрастает интерес к анализу отражения дискурса памяти об этом историческом событии в медиа. Интересны результаты исследования, проведенного А.Ю. Бубновым и А.В. Комплеевым (2020). Ученые провели анализ коллективной памяти о Великой отечественной войне на материалах онлайн-комментариев на портале Ино.СМИ.ру, посвященных обсуждению немецких статей о Прохоровском сражении 1943 года и блокаде Ленинграда 1941-1944 годов. В ходе анализа А.Ю. Бубнов и А.В. Комплеев приходят к выводу, что публикации в СМИ и порожденная ими онлайн-дискуссия демонстрируют столкновение двух принципиально разных версий исторической памяти, при этом преобладающим в немецких СМИ при описании событий Второй мировой войны является «критический дискурс» (Бубнов \& Комплеев, 2020). По мнению ученых это может быть объяснено символами, определяющими национальное сознание, и приводят точку зрения немецкого исследователя Б. Гизена, который предложил разделение коллективных воспоминаний на травматические и триумфальные (Giesen, 2004).

В российском обществе триумфальная память связана с преобладанием в национальном сознании фигуры победителя. Для немецкого же сознания, согласно Б. Гизену, ключевыми являются травматические воспоминания, отраженные в фигурах преступника и жертвы. А.Ю. Бубнов и А.В. Комплеев предполагают, что у немецких журналистов при столкновении с памятью о Победе в российской национальной памяти возникает желание разоблачить «навязчивый» российский триумфализм. В результате возникает «критический дискурс» по отношению к значимым событиям-символам Великой отечественной войны. При этом, согласно результатам анализа онлайн-дискуссий, часть российских интернет-пользователей показывает готовность к принятию новой модели памяти о войне как трагедии и травме, но большая часть рассматривает ее как враждебный акт против национальной памяти (Бубнов \& Комплеев, 2020).

К.К. Фурсов проводит анализ «дискурса вражды» массмедиа на примере исторического дискурса современной национальной памяти относительно событий Второй мировой войны, используя методологию комплексного структурного дискурс-анализа (Фурсов, 2020). В рамках исследования были рассмотрены медиаисточники России (EurAsia, телеканал «Звезда»), Чехии (iROZHLAS), Великобритании (The Telegraph), Украины (Вести), Франции (Le Figaro), Японии (Nihon Keizai), которые в период с декабря 2019 г. по январь 2020 г. освещали годовщину Холокоста, причины начала Второй мировой войны, годовщину освобождения Польши Красной Армией. Проведенный дискурс-анализ позволил К.К. Фурсову разделить проанализированные публикации по цели дискурса политики памяти на несколько типов в соответствии 
со следующими задачами: «отстоять свой национальный взгляд на историю (российские статьи); понять причины исторических споров между Россией и Польшей с обвинением России в историческом ревизионизме (чешские, британские, французские, японские статьи); выяснить, к каким последствиям могут привести выступления, которые опираются на исторические противоречия (украинские статьи)» (Фурсов, 2020, с. 82). На основе дискурс-анализа публикаций исследователь выявляет три основные стратегии в национальной политике памяти: «донести и отстоять свою точку зрения на историю; попытаться разобраться в истории с одновременным обвинением одной или нескольких сторон в историческом ревизионизме; оставить историю историкам из-за ее сложности и привлекательности для политических споров» (с. 82).

К.К. Фурсов отмечает, что дискурс вражды часто апеллирует к принципу объективности в выявлении исторической правды, но при этом ссылки на один и тот же принцип приводят зарубежных и российских авторов к абсолютно противоположным заключениям, так как ими по-разному понимается само понятие «историческая правда» (Фурсов, 2020, с. 84).

\section{Выводы}

Понятие исторической памяти сформировалось в междисциплинарной перспективе под влиянием различных аспектов гуманитарного знания, что способствовало обусловленности этого явления соответствующими культурными, социальными и языковыми факторами. Исследовательский интерес к феномену исторической памяти отражён, в большей мере, в западной научной парадигме, во многом являясь ориентиром для отечественных исследователей.

Историческая память, которую можно понимать как память о событиях прошлого, существует в дискурсе, определяется дискурсом и, в свою очередь, определяет его. Дискурс памяти представляет собой текст, в тематическом плане имеющий отношение к историческим событиям и рассмотренный в ситуации воспоминания об этих событиях. Дискурсивная историческая память может быть определена как реализуемое в дискурсе отражение в сознании человека исторических фактов. Дискурс памяти о конфликте получает отражение и интерпретацию, субъективируясь в современных медиаматериалах и реализуя «политическую память», направленную на выражение интересов, связанных с политической властью.

Обзор эмпирических исследований дискурсивной исторической памяти, проведенных некоторыми зарубежными и отечественными исследователями, показал, что историческая память о мировых войнах, актуализированная в дискурсе европейских СМИ, выступает значимым средством социальной консолидации и формирования национальной идентичности. Интерес исследователей к дискурсу исторической памяти в современных медиа связан как 
с изменением парадигмы изучения соотношения истории и памяти, так и с возрастающим интересом общества к событиям прошлого. При этом методологические подходы к анализу медиадискурса в приведённых в обзоре концепциях различны. Общим дискуссионным вопросом в современной научной полемике остаётся вопрос соотношения национальной памяти и транснациональной / транскультурной памяти, который, возможно, станет основным вектором развития дальнейших исследований.

\section{Авторский вклад}

1. Алёшина Е.Ю. - провела систематизацию и анализ теоретического и практического материала, предложила определение дискурса памяти;

2. Блох М.Я. - автор теории дискурса;

3. Разуваева Т.А. - провела отбор теоретического и практического материала, перевела цитаты;

4. Вагнер X., Комплеев А.В. - участвовали в процессе анализа научной литературы по проблеме исследования.

\section{Благодарности}

Исследование выполнено при финансовой поддержке РФФИ в рамках научного проекта № 20-112-50378\20 «Глобальный конфликт прошлого в современном медиапространстве: историческая память в дискурсивном ракурсе».

Funding: The reported study was funded by RFBR, project number 20-112$50378 \backslash 20$ «Global conflict of the past in contemporary media space: historical memory in a discursive persperctive».

\section{Список литературы}

Artamonov, D. S., Medvedeva, E. N., Tikhonova, S. V., \& Volovikova, M. L. (2021). Holy Selfie as the Channel of Media Memory in the Digital World. Galactica Media: Journal of Media Studies, 3(2), 14-27. doi: $10.46539 / \mathrm{gmd} . \mathrm{v} 3 \mathrm{i} 2.150$

Artamonov, D., Volovikova, M., \& Tikhonova, S. (2019). Media memory in the digital world. SHS Web of Conferences, 72, 01014. doi: 10.1051/shsconf/20197201014

Assmann, A. (2002). Gedächtnis als Leitbegriff der Kulturwissenschaften [Memory as a guiding concept in cultural studies]. In L. Musner \& G. Wunberg (Eds.), Kulturwissenschaften: Forschung - Praxis - Positionen [Cultural Studies: Research-Practice-Positions] (pp. 27-45). Vienna: WUV. (In German).

Assmann, A. (2006). Der lange Schatten der Vergangenheit [The long shadow of the past]. München: C.H. Beck. (In German). 
Assmann, A., \& Assmann, J. (1983). Schrift und Gedächtnis [Writing and Memory]. In A. Assmann, J. Assmann, \& C. Hartmeier (Eds.), Schrift und Gedächtnis. Archäologie der literarischen Kommunikation I [Writing and Memory. Archaeology of Literary Communication I] (pp. 265-284). München: Fink. (In German).

Assmann, A., \& Assmann, J. (1988). Schrift, Tradition und Kultur [Writing, tradition and culture]. In W. Raible (Ed.), Zwischen Festtag und Alltag. Zehn Beiträge zum Thema >Mündlichkeit und Schriftichkeit< [Between Feast Day and Everyday Life. Ten contributions on the theme of 'orality and writtenness'] (pp. 25-30). Tübingen: Narr. (In German).

Assmann, A., \& Assmann, J. (1994). Das Gestern im Heute. Medien und soziales Gedächtnis [Yesterday in Today. Media and Social Memory]. In M. K. Schmidt, J. Siegfried, \& S. Weischenberg (Eds.), Die Wirklichkeit der Medien [The reality of the media]. Opladen: Westdeutscher Verlag (In German).

Assmann, J. (1988). Kollektives Gedächtnis und kulturelle Identität [Collective memory and cultural identity]. In J Assmann \& T. Hölscher (Eds.), Kultur und Gedächtnis [Culture and memory] (pp. 9-19). Frankfurt/M: Suhrkamp. (In German).

Assmann, Jan. (1992). Das kulturelle Gedächtnis: Schrift, Erinnerung und politische Identität in frühen Hochkulturen [Cultural memory: writing, memory and political identity in early civilizations]. München: CH Beck. (In German).

De Cesari, Ch., \& Rigney, A. (Eds.). (2014). Transnational memory: Circulation, articulation, scales (Vol. 19). Berlin: Walter de Gruyter GmbH \& Co KG.

Erll, A. (2004). Medium des kollektiven Gedächtnisses: Ein (erinnerungs-) kulturwissenschaftlicher Kompaktbegriff [Medium of Collective Memory: A Compact Concept in Cultural Studies (of Memory)]. In A. Erll \& A. Nünning, Medien des kollektiven Gedächtnisses. Konstruktivität Historizität - Kulturspezifität [Media of collective memory. Constructivity-Historicity-Culture Specificity] (pp. 3-22). Berlin: de Gruyter. (In German).

Erll, A. (2008). Kollektives Gedächtnis und Erinnerungskulturen [Collective memory and memory cultures]. In A. Nünning \& V. Nünning (Eds.), Einführung in die Kulturwissenschaften. Theoretische Grundlagen - Ansätze - Perspektiven [Introduction to Cultural Studies. Theoretical Foundations-Approaches-Perspectives] (pp. 156-185). Berlin-Heidelberg: Springer-Verlag. (In German).

Erll, A. (2017). Kollektives Gedächtnis und Erinnerungskulturen [Collective memory and memory cultures ]. Stuttgart: Springer-Verlag GmbH Deutschland, J.B. Metzler. (In German).

Esposito, E. (2013). Die Formen des Web-Gedächtnisses. Medien und soziales Gedächtnis [The forms of web memory. Media and social memory]. In R. Lehmann, F. Öchsner, \& G. Sebald, Formen und Funktionen sozialer Gedächtnisse [Forms and functions of social memories] (pp. 91-103). Wiesbaden: Springer VS. (In German).

Fentress, J., \& Wickham, C. (1992). Social Memory. Oxford: Wiley-Blackwell.

Foret, F., \& Calligaro, O. (Eds.). (2012). Conclusion: Resilience and elusiveness of European values. In "European values". Challenges and opportunities for EU governance (pp. 174-180). London: Routledge.

Freeman, L. A., Nienass, B., \& Daniell, R. (2014). Silence, Screen, and Spectacle: Rethinking Social Memory in the Age of Information. New York: Berghahn Books.

Garde-Hansen, J. (2011). Media and Memory. Edinburgh: Edinburgh University Press. 
Garde-Hansen, J., Hoskins, A., \& Reading, A. (2009). Save As... Digital Memories. Basingstoke: Palgrave Macmillan.

Giesen, B. (2004). Triumph and Trauma. Boulder: Paradigm publishers.

Grosz, E. A. (1999). Becomings: Explorations in Time, Memory, and Futures. Ithaca/NY: Cornell University Press.

Halbwachs, M. (1950). La Mémoire collective [The Collective Memory]. Paris: Presses Universitaires de France. (In French).

Halbwachs, M. (1966). Das Gedächtnis und seine sozialen Bedingungen [Memory and its social conditions]. Berlin: Luchterhand. (In German).

Hein, D. (2009). Erinnerungskulturen online. Angebote, Kommunikatoren und Nutzer von Websites zu Nationalsozialismus und Holocaust [Cultures of remembrance online. Offers, Communicators and Users of Websites on National Socialism and the Holocaust]. Konstanz: UVK. (In German).

Hepp, A. (2011). Medienkultur. Die Kultur mediatisierter Welten [Media Culture. The Culture of Mediatized Worlds]. Wiesbaden: VS. (In German).

Horton, A., \& Usero, A. (2020, May 8). Defense Secretary Esper stood beside World War II veteransWithout a mask. Washington Post. Retrieved from https://www.washingtonpost.com/ national-security/2020/05/08/wwiimemorial-trump-esper/

Huyssen, A. (1995). Twilight Memories: Marking Time in a Culture of Amnesia. New York: Routledge.

IISler, R. A. (2017). Kulturelles Gedächtnis [Cultural memory]. In L. Kühnhardt \& T. Mayer (Eds.), Bonner Enzyklopädie der Globalität [Bonn Encyclopedia of Globality] (pp. 902-922). Wiesbaden: Springer Fachmedien Wiesbaden GmbH. (In German).

Jacke, Ch., \& Zierold, M. (2015). Gedächtnis und Erinnerung [Memory and recollection]. In A. Hepp (Ed.), Handbuch Cultural Studies und Medienanalyse [Handbook Cultural Studies and Media Analysis] (pp. 79-89). Wiesbaden: Springer Fachmedien. (In German).

Kammen, M. (1995). Contested Values: Democracy and Diversity in American Culture. St. Martin's Press, Inc.

Keightley, E., \& Reading, A. (2014). Mediated mobilities. Media, Culture E Society, 36(3), 285-301. doi: $\underline{10.1177 / 0163443713517731}$

Kocka, J., \& Nolte, P. (2000). Historische Sozialwissenschaft heute [Historical social science today]. In Perspektiven der Gesellschaftsgeschichte [Perspectives of social history] (pp. 5-24). München: C.H. Beck. (In German).

Le, E., Radut-Gaghi, L., Silletti, A. M., \& Wagner, H. (2021). Media Discourse of Commemoration. The Centenary of World War One in Europe. Palgrave Macmillan.

Mayer-Schönberger, V. (2010). Die Tugend des Vergessens in digitalen Zeiten: Delete [The virtue of forgetting in digital times: Delete]. Berlin: Berlin University Press. (In German).

Pethes, N., \& Ruchatz, J. (2001). Gedächtnis und Erinnerung: Ein interdisziplinäres Lexikon [Memory and recollection: An interdisciplinary lexicon]. Reinbek bei Hamburg: Rowohlt Taschenbuch. (In German).

Quiros, A. L., \& Strasburg, J. (2020). Americans fighting for two victories in World War II only got one. Washington Post. Retrieved from https://www.washingtonpost.com/outlook/2020/05/08/ americans-fighting-two-victories-world-war-ii-only-got-one/ 
Radonić, L., \& Uhl, H. (2016). Gedächtnis im 21. Jahrhundert. Zur Neuverhandlung eines kulturwissenschaftlichen Leitbegriffs [Memory in the 21st Century. On the Renegotiation of a Guiding Concept in Cultural Studies]. Bielefeld: Verlag. (In German).

Reading, A. (2014). Seeing red: A political economy of digital memory. Media, Culture E Society, 36(6), 748-760. doi: $\underline{10.1177 / 0163443714532980}$

Reading, A. (2016). Gender and memory in the globital age. Springer.

Rigney, A. (2014). Ongoing: Changing Memory and the European Project. In Ch. De Cesari \& A. Rigney (Eds.), Transnational Memory. Circulation, Articulation, Scales (pp. 339-359). Berlin/Boston: de Gruyter.

Rüsen, J., \& Jaeger, F. (2001). Erinnerungskultur [Remembrance culture]. In K.-R. Korte \& W. Weidenfeld (Eds.), Deutschland-TrendBuch. Fakten und Orientierungen [Germany-TrendBook. Facts and Orientations] (pp. 397-428). Wiesbaden: Springer Fachmedien Wiesbaden GmbH. (In German).

Sangar, E. (2015). From "memory wars" to shared identities: Conceptualizing the transnationalisation of collective memory. The Tocqueville Review, 36(2), 65-93.

Sebald, G. (2018). (Digitale) Medien und Gedächtnis - aus der Perspektive einer Gedächtnissoziologie [(Digital) Media and Memory-From the Perspective of a Sociology of Memory]. In G. Sebald \& M.-K. Döbler (Eds.), (Digitale) Medien und soziale Gedächtnisse [(Digital) media and social memories] (pp. 29-51). Wiesbaden: Springer Fachmedien Wiesbaden GmbH. (In German).

Sommer, V. (2018). Mediatisierte Erinnerungen. Medienwissenschaftliche Perspektiven für eine Theoretisierung digitaler Erinnerungsprozesse [Mediatized Memories. Media Studies Perspectives for a Theorization of Digital Memory Processes]. In G. Sebald \& M.-K. Döbler (Eds.), (Digitale) Medien und soziale Gedächtnisse [(Digital) media and social memories] (pp. 53-79). Wiesbaden: Springer Fachmedien Wiesbaden GmbH. (In German).

Sondergeld, B. (2010). Spanische Erinnerungskultur. Die Assmann'sche Theorie des kulturellen Gedächtnisses und der Bürgerkrieg 1936-1939 [Spanish Memory Culture. Assmann's Theory of Cultural Memory and the Civil War 1936-1939.]. Wiesbaden: GWV Fachverlage GmbH. (In German).

Van Dijck, J. (2007). Mediated memories in the digital age. Stanford/Ca.: Stanford University Press.

Van Dijck, J. (2013). The culture of connectivity: A critical history of social media. Oxford/New York: Oxford University Press.

Zierold, M. (2006). Gesellschaftliche Erinnerung. Eine medienkulturwissenschaftliche Perspektive [Social memory. A Media Cultural Studies Perspective]. Berlin: de Gruyter. (In German).

Алёшина, Е. Ю. (2021). Падение берлинской стены (9 ноября 1989 года) в современных СМИ: Дискурс памяти. Язык как основа современного межкультурного взаилодействия: материалы VII Международной научно-практической конференции 30 ноября - 3 декабря 2020 года, 211-218. Пенза: ПензГТУ.

Аникин, Д. А., Бубнов, А. Ю., \& Комплеев, А. В. (2020). Российское историческое общество как актор символической политики: Институциональные особенности и мемориальные риски. Известия высших учебных заведений. Поволжский регион. Гуманитарные науки, (1), 114-124.

Артамонов, Д. С., \& Тихонова, С. В. (2020). Гараж истории: Цифровой поворот «независимых исторических исследований». Диалог со временем, (72), 237-254.

Ассман, А. (2014). Длинная тень прошлого: Мемориальная культура и историческая политика. Москва: Новое Литературное Обозрение. 
Ассман, Я. (2004). Культурная палять. Писъмо, палять о прошлом и политическая идентичность в высоких культурах древности. Москва: Языки славянской культуры.

Барабанов, О. (2020). Образ войны в исторической памяти. Извлечено от Российская газета website: https://rg.ru/2020/05/08/obrazy-vojny-v-istoricheskoj-pamiati.html

Блох, М. Я. (2013). Дискурс и системное языкознание. Язык. Культура. Речевое общение, (1), 5-11.

Бубнов А. Ю., \& Комплеев, А. В. (2020). Российско-немецкая «война памяти»: Анализ современной онлайн дискуссии о Великой Отечественной войне. Наука. Общество. Оборона, 8(2). doi: $\underline{10.24411 / 2311-1763-2020-10233}$

Вагнер, Х., \& Алешина, Е. Ю. (2019). Отражение прошлого Европы в онлайн-медиа. Пенза; Фленсбург; Сержи-Понтуаз: Пензенский государственный университет.

Васильев, А. (2009). Теория социальной памяти Аби Варбурга Между философией культуры и историей искусства. Искусствознание, (1-2), 16-39.

Васильев, А. Г. (2014). Воплощенная память: Коммеморативный ритуал в социологии Э. Дюркгейма. Социологическое обозрение, 13(2), 141-167.

Глебова, И. И., Большакова, О. В., \& Минц, М. М. (2013). Россия в Первой мировой войне: Новые направления исследований. Москва: ИНИОН РАН.

Давыдов, И. П. (2015). Архетип коллективной памяти (Рецензия на книгу: Ассман Алейда. Длинная тень прошлого: Мемориальная культура и историческая политика). Вестник Ленинградского государственного университета им. А.С. Пушкина, 2(2), 377-387.

Иванов, А. Г., Тихонова, С. В., Линченко, А. А., \& Полякова, И. П. (2020). Мифы о прошлом в современной медиасреде: Практики конструирования, механизмы воздействия, перспективы использования. Санкт-Петербург: Алетейя.

Козлов, В. П. (2006). Последняя война Российской илперии: Россия, мир накануне, в ходе и после Первой мировой войны по документам российских и зарубежных архивов: Материалы Международной научной конференции 7-8 сентября 2004 года. Москва: Наука.

Коротецкая, Л. В. (2018). Социальная память: Социологический анализ дискурса прошлого в немецком самосознании (Диссертация). Московский государственный институт международных отношений, Москва.

Лотман, Ю. М. (1992). Память в культурологическом освещении. Избранные статьи (Т. 1). Таллин: Таллин.

Манойло, А. В. (2013). Политические конфликты в международных отношениях и мировой политике. Мир и политика, (2), 71-82.

Мединский, В. (2018). В камне, в бронзе, в живой памяти. Извлечено от Российская газета website: https://rg.ru/2018/11/10/v-kamne-v-bronze-v-zhivoj-pamiati.html

Нора, П. (1999). Франция-память. Санкт-Петербург: Издательство Санкт-Петербургского университета.

Рикёр, П. (2004). Память, история, забвение. Москва: Издательство гуманитарная литература.

Сабанчеев, Р. Ю. (2018). Концепция «мест памяти» Пьера Нора как способ исторической реконструкции. Гуманитарные исследования в Восточной Сибири и на Дальнем Востоке, (1), 33-38.

Федорова, М. М. (2018). История/память: «трудная» дилемма. История Философии, 23(1), 108-121. 
Фурсов, К. К. (2020). Современные массмедиа о событиях Второй мировой войны: Структурный анализ дискурса вражды. Научный журнал «Дискурс-ПИ», 3(40). doi: 10.24411/1817-9568$\underline{2020-10305}$

\section{References}

Aleshina, E. Yu. (2021). The Fall of the Berlin Wall (November 9, 1989) in Contemporary Media: A Discourse of Memory. Language as the basis of modern intercultural interaction: Proceedings of the VII International Scientific and Practical Conference November 30 - December 3, 2020, 211-218. Penza: Penza State Technical University. (In Russian).

Anikin, D. A., Bubnov, A. Yu., \& Kompleyev, A. V. (2020). The Russian Historical Society as an Actor in Symbolic Politics: Institutional Features and Memorial Risks. Proceedings of Higher Educational Institutions. Volga Region. Humanities, (1), 114-124. (In Russian).

Artamonov, D. S., \& Tikhonova, S. V. (2020). History Garage: The Digital Twist of "Independent Historical Research". Dialogue with Time, (72), 237-254. (In Russian).

Artamonov, D. S., Medvedeva, E. N., Tikhonova, S. V., \& Volovikova, M. L. (2021). Holy Selfie as the Channel of Media Memory in the Digital World. Galactica Media: Journal of Media Studies, 3(2), 14-27. doi: $10.46539 /$ gmd.v3i2.150

Artamonov, D., Volovikova, M., \& Tikhonova, S. (2019). Media memory in the digital world. SHS Web of Conferences, 72, 01014. doi: 10.1051/shsconf/20197201014

Assman, A. (2014). The Long Shadow of the Past: Memorial Culture and Historical Politics. Moscow: Novoye Literaturnoye Obozreniye. (In Russian).

Assman, J. (2004). Cultural Memory. Writing, Memory of the Past, and Political Identity in the High Cultures of Antiquity. Moscow: Languages of Slavic Culture. (In Russian).

Assmann, A. (2002). Gedächtnis als Leitbegriff der Kulturwissenschaften [Memory as a guiding concept in cultural studies]. In L. Musner \& G. Wunberg (Eds.), Kulturwissenschaften: Forschung - Praxis - Positionen [Cultural Studies: Research-Practice-Positions] (pp. 27-45). Vienna: WUV. (In German).

Assmann, A. (2006). Der lange Schatten der Vergangenheit [The long shadow of the past]. München: C.H. Beck. (In German).

Assmann, A., \& Assmann, J. (1983). Schrift und Gedächtnis [Writing and Memory]. In A. Assmann, J. Assmann, \& C. Hartmeier (Eds.), Schrift und Gedächtnis. Archäologie der literarischen Kommunikation I [Writing and Memory. Archaeology of Literary Communication I] (pp. 265284). München: Fink. (In German).

Assmann, A., \& Assmann, J. (1988). Schrift, Tradition und Kultur [Writing, tradition and culture]. In W. Raible (Ed.), Zwischen Festtag und Alltag. Zehn Beiträge zum Thema >Mündlichkeit und Schriftlichkeit< [Between Feast Day and Everyday Life. Ten contributions on the theme of 'orality and writtenness'] (pp. 25-30). Tübingen: Narr. (In German).

Assmann, A., \& Assmann, J. (1994). Das Gestern im Heute. Medien und soziales Gedächtnis [Yesterday in Today. Media and Social Memory]. In M. K. Schmidt, J. Siegfried, \& S. Weischenberg (Eds.), Die Wirklichkeit der Medien [The reality of the media]. Opladen: Westdeutscher Verlag (In German). 
Assmann, J. (1988). Kollektives Gedächtnis und kulturelle Identität [Collective memory and cultural identity]. In J Assmann \& T. Hölscher (Eds.), Kultur und Gedächtnis [Culture and memory] (pp. 9-19). Frankfurt/M: Suhrkamp. (In German).

Assmann, Jan. (1992). Das kulturelle gedächtnis: Schrift, erinnerung und politische identität in frühen hochkulturen [Cultural memory: writing, memory and political identity in early civilizations]. München: CH Beck. (In German).

Barabanov, O. (2020). The image of war in the historical memory. Retrieved from Rossiyskaya Gazeta website: https://rg.ru/2020/05/08/obrazy-vojny-v-istoricheskoj-pamiati.html (In Russian).

Blokh, M. Y. (2013). Discourse and Systemic Linguistics. Language. Culture. Speech Communication, (1), 5-11. (In Russian).

Bubnov, A. Y., \& Kompleev, A. V. (2020). The Russian-German "war of memory": An Analysis of Contemporary Online Discussion of the Great Patriotic War. Science. Society. Defence, 8(2). doi: $\underline{10.24411 / 2311-1763-2020-10233}$ (In Russian).

Davydov, I. P. (2015). The Archetype of Collective Memory (Review of the book: Assmann Aleida. The Long Shadow of the Past: Memorial Culture and Historical Politics). Bulletin of A.S. Pushkin Leningrad State University, 2(2), 377-387. (In Russian).

De Cesari, Ch., \& Rigney, A. (Eds.). (2014). Transnational memory: Circulation, articulation, scales (Vol. 19). Berlin: Walter de Gruyter GmbH \& Co KG.

Erll, A. (2004). Medium des kollektiven Gedächtnisses: Ein (erinnerungs-) kulturwissenschaftlicher Kompaktbegriff [Medium of Collective Memory: A Compact Concept in Cultural Studies (of Memory)]. In A. Erll \& A. Nünning, Medien des kollektiven Gedächtnisses. Konstruktivität Historizität - Kulturspezifität [Media of collective memory. Constructivity-Historicity-Culture Specificity] (pp. 3-22). Berlin: de Gruyter. (In German).

Erll, A. (2008). Kollektives Gedächtnis und Erinnerungskulturen [Collective memory and memory cultures]. In A. Nünning \& V. Nünning (Eds.), Einführung in die Kulturwissenschaften. Theoretische Grundlagen - Ansätze - Perspektiven [Introduction to Cultural Studies. Theoretical Foundations-Approaches-Perspectives] (pp. 156-185). Berlin-Heidelberg: Springer-Verlag. (In German).

Erll, A. (2017). Kollektives Gedächtnis und Erinnerungskulturen [Collective memory and memory cultures ]. Stuttgart: Springer-Verlag GmbH Deutschland, J.B. Metzler. (In German).

Esposito, E. (2013). Die Formen des Web-Gedächtnisses. Medien und soziales Gedächtnis [The forms of web memory. Media and social memory]. In R. Lehmann, F. Öchsner, \& G. Sebald, Formen und Funktionen sozialer Gedächtnisse [Forms and functions of social memories] (pp. 91-103). Wiesbaden: Springer VS. (In German).

Fedorova, M. M. (2018). History/Memory: A “difficult” dilemma. History of Philosophy, 23(1), 108-121. (In Russian).

Fentress, J., \& Wickham, C. (1992). Social Memory. Oxford: Wiley-Blackwell.

Foret, F., \& Calligaro, O. (Eds.). (2012). Conclusion: Resilience and elusiveness of European values. In "European values". Challenges and opportunities for EU governance (pp. 174-180). London: Routledge.

Freeman, L. A., Nienass, B., \& Daniell, R. (2014). Silence, Screen, and Spectacle: Rethinking Social Memory in the Age of Information. New York: Berghahn Books. 
Fursov, K. K. (2020). Modern Media on the Events of World War II: A Structural Analysis of the Discourse of Enmity. Scientific journal "Discourse-PI", 3(40). doi: 10.24411/1817-9568-2020$\underline{10305}$ (In Russian).

Garde-Hansen, J. (2011). Media and Memory. Edinburgh: Edinburgh University Press.

Garde-Hansen, J., Hoskins, A., \& Reading, A. (2009). Save As... Digital Memories. Basingstoke: Palgrave Macmillan.

Giesen, B. (2004). Triumph and Trauma. Boulder: Paradigm publishers.

Glebova, I. I., Bolshakova, O. V., \& Minz, M. M. (2013). Russia in World War I: New Directions for Research. Moscow: INION RAS.. (In Russian).

Grosz, E. A. (1999). Becomings: Explorations in Time, Memory, and Futures. Ithaca/NY: Cornell University Press.

Halbwachs, M. (1950). La Mémoire collective [The Collective Memory]. Paris: Presses Universitaires de France. (In French).

Halbwachs, M. (1966). Das Gedächtnis und seine sozialen Bedingungen [Memory and its social conditions]. Berlin: Luchterhand. (In German).

Hein, D. (2009). Erinnerungskulturen online. Angebote, Kommunikatoren und Nutzer von Websites zu Nationalsozialismus und Holocaust [Cultures of remembrance online. Offers, Communicators and Users of Websites on National Socialism and the Holocaust]. Konstanz: UVK. (In German).

Hepp, A. (2011). Medienkultur. Die Kultur mediatisierter Welten [Media Culture. The Culture of Mediatized Worlds]. Wiesbaden: VS. (In German).

Horton, A., \& Usero, A. (2020, May 8). Defense Secretary Esper stood beside World War II veteransWithout a mask. Washington Post. Retrieved from https://www.washingtonpost.com/ national-security/2020/05/08/wwiimemorial-trump-esper/

Huyssen, A. (1995). Twilight Memories: Marking Time in a Culture of Amnesia. New York: Routledge.

Ißler, R. A. (2017). Kulturelles Gedächtnis [Cultural memory]. In L. Kühnhardt \& T. Mayer (Eds.), Bonner Enzyklopädie der Globalität [Bonn Encyclopedia of Globality] (pp. 902-922). Wiesbaden: Springer Fachmedien Wiesbaden GmbH. (In German).

Ivanov, A. G., Tikhonova, S. V., Linchenko, A. A., \& Polyakova, I. P. (2020). Myths about the Past in the Modern Media Environment: Practices of Construction, Mechanisms of Influence, and Prospects for Use. St. Petersburg: Aletheia. (In Russian).

Jacke, Ch., \& Zierold, M. (2015). Gedächtnis und Erinnerung [Memory and recollection]. In A. Hepp (Ed.), Handbuch Cultural Studies und Medienanalyse [Handbook Cultural Studies and Media Analysis] (pp. 79-89). Wiesbaden: Springer Fachmedien. (In German).

Kammen, M. (1995). Contested Values: Democracy and Diversity in American Culture. St. Martin's Press, Inc.

Keightley, E., \& Reading, A. (2014). Mediated mobilities. Media, Culture \& Society, 36(3), 285-301. doi: $10.1177 / 0163443713517731$

Kocka, J., \& Nolte, P. (2000). Historische Sozialwissenschaft heute [Historical social science today]. In Perspektiven der Gesellschaftsgeschichte [Perspectives of social history] (pp. 5-24). München: C.H. Beck. (In German). 
Korotetskaya, L. V. (2018). Social Memory: A Sociological Analysis of the Discourse of the Past in German Self-Consciousness (Dissertation). Moscow State Institute of International Relations, Moscow. (In Russian).

Kozlov, V. P. (2006). The Last War of the Russian Empire: Russia, the World on the Eve, During, and After the First World War According to Documents from Russian and Foreign Archives: Proceedings of the International Scientific Conference, September 7-8, 2004. Moscow: Nauka. (In Russian).

Le, E., Radut-Gaghi, L., Silletti, A. M., \& Wagner, H. (2021). Media Discourse of Commemoration. The Centenary of World War One in Europe. Palgrave Macmillan.

Lotman, Y. M. (1992). Memory in Cultural Illumination. Selected articlesu (Vol. 1). Tallinn. (In Russian).

Manoilo, A. V. (2013). Political Conflicts in International Relations and World Politics. Peace and politics, (2), 71-82. (In Russian).

Mayer-Schönberger, V. (2010). Die Tugend des Vergessens in digitalen Zeiten: Delete [The virtue of forgetting in digital times: Delete]. Berlin: Berlin University Press. (In German).

Medinsky, V. (2018). B In stone, in bronze, in living memory. Retrieved from Rossiyskaya Gazeta website: https://rg.ru/2018/11/10/v-kamne-v-bronze-v-zhivoj-pamiati.html (In Russian).

Nora, P. (1999). France-memory. St. Petersburg: St. Petersburg University Press. (In Russian).

Pethes, N., \& Ruchatz, J. (2001). Gedächtnis und Erinnerung: Ein interdisziplinäres Lexikon [Memory and recollection: An interdisciplinary lexicon]. Reinbek bei Hamburg: Rowohlt Taschenbuch. (In German).

Quiros, A. L., \& Strasburg, J. (2020). Americans fighting for two victories in World War II only got one. Washington Post. Retrieved from https://www.washingtonpost.com/outlook/2020/05/08/ americans-fighting-two-victories-world-war-ii-only-got-one/

Radonić, L., \& Uhl, H. (2016). Gedächtnis im 21. Jahrhundert. Zur Neuverhandlung eines kulturwissenschaftichen Leitbegriffs [Memory in the 21st Century. On the Renegotiation of a Guiding Concept in Cultural Studies]. Bielefeld: Verlag. (In German).

Reading, A. (2014). Seeing red: A political economy of digital memory. Media, Culture E Society, 36(6), 748-760. doi: $\underline{10.1177 / 0163443714532980}$

Reading, A. (2016). Gender and memory in the globital age. Springer.

Ricoeur, P. (2004). Memory, History, Oblivion. Moscow: Publisher of Humanitarian Literature. (In Russian).

Rigney, A. (2014). Ongoing: Changing Memory and the European Project. In Ch. De Cesari \& A. Rigney (Eds.), Transnational Memory. Circulation, Articulation, Scales (pp. 339-359). Berlin/Boston: de Gruyter.

Rüsen, J., \& Jaeger, F. (2001). Erinnerungskultur [Remembrance culture]. In K.-R. Korte \& W. Weidenfeld (Eds.), Deutschland-TrendBuch. Fakten und Orientierungen [Germany-TrendBook. Facts and Orientations] (pp. 397-428). Wiesbaden: Springer Fachmedien Wiesbaden GmbH. (In German).

Sabancheev, R. Yu. (2018). Pierre Nora's concept of "places of memory" as a mode of historical reconstruction. Humanitarian Studies in Eastern Siberia and the Far East, (1), 33-38. (In Russian).

Sangar, E. (2015). From "memory wars" to shared identities: Conceptualizing the transnationalisation of collective memory. The Tocqueville Review, 36(2), 65-93. 
Sebald, G. (2018). (Digitale) Medien und Gedächtnis - aus der Perspektive einer Gedächtnissoziologie [(Digital) Media and Memory-From the Perspective of a Sociology of Memory]. In G. Sebald \& M.-K. Döbler (Eds.), (Digitale) Medien und soziale Gedächtnisse [(Digital) media and social memories] (pp. 29-51). Wiesbaden: Springer Fachmedien Wiesbaden GmbH. (In German).

Sommer, V. (2018). Mediatisierte Erinnerungen. Medienwissenschaftliche Perspektiven für eine Theoretisierung digitaler Erinnerungsprozesse [Mediatized Memories. Media Studies Perspectives for a Theorization of Digital Memory Processes]. In G. Sebald \& M.-K. Döbler (Eds.), (Digitale) Medien und soziale Gedächtnisse [(Digital) media and social memories] (pp. 53-79). Wiesbaden: Springer Fachmedien Wiesbaden GmbH. (In German).

Sondergeld, B. (2010). Spanische Erinnerungskultur. Die Assmann'sche Theorie des kulturellen Gedächtnisses und der Bürgerkrieg 1936-1939 [Spanish Memory Culture. Assmann's Theory of Cultural Memory and the Civil War 1936-1939.]. Wiesbaden: GWV Fachverlage GmbH. (In German).

Van Dijck, J. (2007). Mediated memories in the digital age. Stanford/Ca.: Stanford University Press.

Van Dijck, J. (2013). The culture of connectivity: A critical history of social media. Oxford/New York: Oxford University Press.

Vasiliev, A. (2009). Abi Warburg's Theory of Social Memory. Between the philosophy of culture and the history of art. Art History, (1-2), 16-39. (In Russian).

Vasiliev, A. G. (2014). Incarnate Memory: Commemorative Ritual in the Sociology of Durkheim. Sociological Review, 13(2), 141-167. (In Russian).

Wagner, H., \& Aleshina, E. Yu. (2019). Reflections of Europe's Past in Online Media. Penza; Flensburg; Cergy-Pontoise: Penza State University. (In Russian).

Zierold, M. (2006). Gesellschaftliche Erinnerung. Eine medienkulturwissenschaftliche Perspektive [Social memory. A Media Cultural Studies Perspective]. Berlin: de Gruyter. (In German). 